\title{
Benign fibrous histiocytoma, case report
}

\author{
Monica D’Amato Gutiérrez ${ }^{1}$, Natalia Andrea Valencia Zuluaga ${ }^{2}$, Andrea Parra Buitrago ${ }^{3 *}$ and David Andrés Espinal Botero ${ }^{4}$ \\ ${ }^{1}$ Pediatrics Resident, Universidad Pontificia Bolivariana, Medellín, Antioquia, Colombia \\ ${ }^{2}$ Pediatrician, Pablo Tobon Uribe Hospital, fellowship pediatric oncology, Colombia \\ ${ }^{3}$ Pediatrician, Department of Pediatrics Hospital Pablo Tobon Uribe and School of Medicine Pontificia Bolivariana, Colombia \\ ${ }^{4}$ Pediatrician, Pablo Tobon Uribe Hospital Medellín, Colombia
}

\begin{abstract}
The benign fibrous histiocytoma or fibrohistiocytoma is a benign neoplasm involving fibroblasts and histiocytes. The tumor occurs most often in the skin of the extremities, rarely commits deep soft tissues and parenchymal organs. The diagnosis can be very difficult and is histologically confirmed only. We present a case of a male patient of 14 months old, who presents with ascites due an unresectable benign fibrous histiocytoma. Was managed with four cycles of chemotherapy ARST protocol without evidence of improvement.
\end{abstract}

\section{Introduction}

The benign fibrous histiocytoma (BFH) is one of the most common mesenchymal tumors, it is believed that originates in histiocytes, but different findings of the lesion microscopically has led to the use of numerous alternative terms for it, including dermatofibroma, sclerosing hemangioma, xanthogranuloma, fibroxanthoma, and nodular subepidermal fibrosis [1].

This tumor occurs most often in the dermis of the extremities, but also can be found sporadically in the soft tissue and parenchymal organs. It often develops as a painless mass with nonspecific symptoms caused by interference with the normal anatomy and physiology of the area in which they arise [2].

$\mathrm{BFH}$ diagnosis is often a challenge and must be based on the combination of light microscopy and immunohistochemistry. Extensive research, including clinical history, physical examination, laboratory tests and imaging studies are essential to establish the diagnosis and treatment.

We present an unusual case of $\mathrm{BFH}$, where its parenchymal involvement makes it impossible for resection, which overshadows the prognosis of this patient.

\section{Case presentation}

This is a 14 months of old male patient from coastal region of Colombia; was born at term, by uncomplicated cesarean delivery with no pathologic past medical history. At 3 months of life during the evaluation by an umbilical hernia, was found ascites and hepatomegaly, requiring five therapeutic paracentesis. The initial laboratory with elevation of transaminases, and cholestatic pattern, elevated coagulation tests and mild proteinuria. Hepatotropic viruses were negative, infectious screening negative, and screening for mucopolysaccharidosis and carbohydrate or amino acids metabolism abnormalities were also negative (Table 1).

In abdominal ultrasound and abdominal tomography it's found a cystic image in mesogastrium and hypogastrium, with mild hepatosplenomegaly and signs of mild portal hypertension, with collateralization of the umbilical vein. He is admitted to our institution for additional studies. In the new abdominal ultrasound is found diffuse hepatomegaly, mild splenomegaly, and in the renal pelvis a heterogeneous lesion ill-defined borders, no infiltrative of $28 * 38 * 28$ millimeters, and at the right adrenal gland an hypoechoic lesion of $32 *$ $23 * 28$ millimeters, with cleavage planes with the liver and kidney, and also thickening of the peritoneum.

So an abdominal MRI is perfomed which shows peritoneal walls thickening and ascites with thickened fluid, hepatomegaly with heterogeneous liver, and in the right adrenal gland and heterogeneous nodular lesion with small foci of necrosis (Figure 1).

The patient is seen by specialties, including paediatrics, genetics, hepatology, infectious diseases, and conceptualizes that the clinical, radiological and biochemical findings are not consistent with glycogen storage disease. Also we rule out tuberculosis with negative skin test and negative sputum smear. Because the imaging findings, a laparoscopy for peritoneum biopsy is done to rule out tumor and chronic infectious process. Crultures were negative for infectious process; and the pathology biopsy reports Fibrohistiocytoma benign in peritoneum.

Table 1. Laboratory.

\begin{tabular}{|c|c|c|c|c|c|c|}
\hline Age (months) & AST / ALT & BT /BD & AP & Albumin & Calcium & Glucose \\
\hline 5 & $68 / 30$ & $3.8 / 2.36$ & 214 & Normal & & Normal \\
\hline 11 & $55 / 38$ & & & 3.44 & & Normal \\
\hline 12 & $22 / 18$ & & & 0.9 & & \\
\hline 14 & $53 / 32$ & $0.64 / 0.26$ & 325 & 2.7 & 15.1 & 126 \\
\hline
\end{tabular}

AST/ALT: Aspartate/Alanine aminotransferase BT: Total Bilirrubin BD: Direct Bilirrubine AP: Alkaline phosphatase.

Correspondence to: Andrea Parra Buitrago, Pediatrician, Department of Pediatrics Hospital Pablo Tobon Uribe and School of Medicine Pontificia Bolivariana, Colombia, Tel: (574) 4114745; E-mail: andreaparrab@gmail.com

Key words: benign fibrous histiocytoma, fibrohistiocytoma, soft tissue neoplasms Received: July 27, 2016; Accepted: August 18, 2016; Published: August 22, 2016 
Pediatric surgery is consulted and given the extensive abdominal compromise the lesion is not amenable to surgical handling therefore patient is refered to pediatric oncology,. The decision to start chemotherapy is made and extension studies looking for metastases were negative.

ARST 0332 chemotherapy protocol is initiated by four cycles (ifosfamide, mesna, doxorubicin), then a control abdominal MRI is made describing heterogeneous diffuse hepatomegaly without focal lesions, no changes in the hypodense lesion with poorly defined edges that engages the lower pole of the left kidney with extension into the renal sinus $(25 * 16 * 20$ millimeters) and in the right adrenal gland a heterogeneous discrete lesion with necrosis, is $35 * 26 * 32 \mathrm{~mm}$ (before $31 * 27 * 26$ ) (Figure 2).

Due this is a patient with progressive ascites, growing abdominal distention without dyspnea or respiratory impairment, and with no improvement in abdominal mass after chemotherapy, it was considered this is a not a chemotherapy sensitive tumor and with the family and for the benefit of the patient, given the adverse effects of chemotherapy and little response to this, the decision of continue handling by group of pain and palliative care was made.

\section{Discussion}

The benign fibrous histiocytoma (HFB) or fibrohistiocytoma is one of the most common mesenchymal tumors in adults, but in children are few report cases. 6 It is a variant of cutaneous histiocytoma or dermatofibroma described by Fletcher in 1990 as a tumor originating in the subcutaneous tissue [2-5].
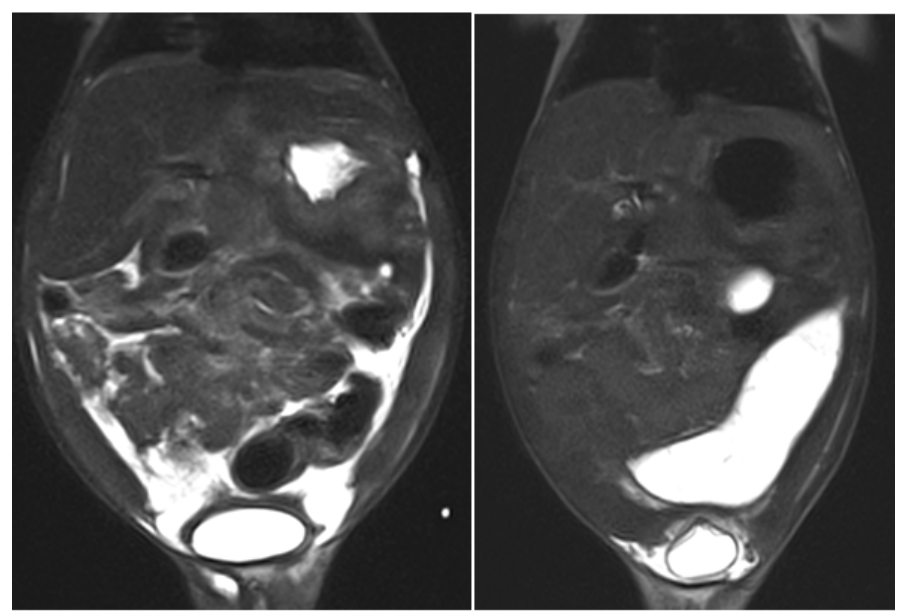

Figure 1. Abdominal MRI.

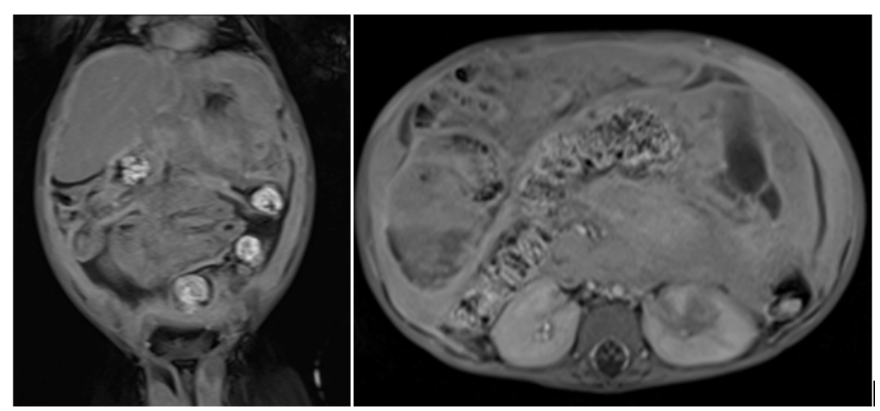

Figure 2. Control abdominal MRI.
It is a tumor of fibroblasts and multinucleated cells resembling histiocytes (dendritic cells of the dermis), described in the dermis with extension to subcutaneous tissue, but respecting epidermis. Sometimes full of fat cells, so too have described as xanthoma or fibroxanthoma [6].

Cause is uncertain, there is even debate among pathologists about whether it is a true tumor, or a reactive process or a defect in cell development.

Its main form of presentation is in the skin, both children and adults. It has been reported that may arise after minor trauma or an insect bite or chronic infection, even suggesting a benign reactive proliferation of cells. HFB as aneurysmal variants, angiomatoid, atypical cell, epithelioid and juvenile xanthogranuloma described [7].

The differential diagnosis is storiform pattern with dermatofibrosarcoma protuberans (DFSP) (major cellular component, not epsonjosas cells), malignant fibrous histiocytoma (infiltrative, marked pleomorphism and mitotic activity) and hemangiopericytoma. atypical fibroxanthoma, Kaposi's sarcoma (vascular tumor with extravasation of red blood cells), leiomyoma or leiomyosarcoma (muscle fibers), myofibroblastic sarcoma (infiltrative, desmin positive), and Rosai- Dorman disease (CD68 positive histiocytes, no storiform) $[6,8]$.

There are few cases in children is more common in middle-aged adults, and women $[2,5,9]$.

Primarily it manifests as primary skin lesions in sun-exposed areas and bones in the lower extremities, face and neck, and in some rare cases abdominal wall. The skin lesion is usually a papule, solitary and slow growth; that the onset is asymptomatic but then may present with pain, which progresses to chronic even for years [6-11].

Although the soft tissue in the dermis is the predominant source site, the tumor may originate from parenchymal organs $<1-2 \%$ of cases, as in this patient [12-15].

Since clinical is unspecific, and that no other cases described with abdominal symptoms, it is imperative for proper diagnosis and pathology the inmunohistomquímica [5].

In fact differentiation with dermatofibrosarcoma protuberans (DFSP) and malignant fibrous histiocytoma (MFH), it has been improved with immunohistochemical staining methods.

From the point of view Immunohistochemical these tumors do not show monocyte/macrophage differentiation and histogenesis remains uncertain [8].

Factor XIIIa expressed. CD34 is usually negative, but found cases where it is CD34 positive especially in the periphery of the lesion, and more common in cell variant. It is variable and CD68 positivity for smooth muscle actin [16].

Being chronically presentation, most samples are taken on an outpatient basis and cannot take adequate samples for a complete diagnosis, which has limited determine whether there is a genetic component.

The literature describes only a few cases of HFB in abdominal cavity, and have been metastatic skin lesions [9].

No reports were found tumor in the abdominal cavity or peritoneum as primary lesion. As it presented here.

It has been classified by the WHO as a tumor of intermediate grade 
malignancy; with a great local aggressiveness but low rate mestástasis $[2,4]$.

Generally the prognosis is good, and can be totally resected management, as reported local recurrence is low. And although the treatment of choice for BFHS is the wide resection of the tumor, resulting in an excellent prognosis and low recurrence rate described primary skin lesions of the face and atypical variants, such as cell and aneurysmal that It limits its surgical management $[2,5,11]$.

\section{Conclusion}

There are no reports in children and adults benign fibrous histiocytoma of peritoneum, only a few cases of malignant histiocytoma. Probably the primary lesion develops in peritoneum, because its interstice has fibroblast cell. This study gives the opportunity to present a negative result, which has rarely been reported in other studies. Because it is a rare case of a HFB peritoneum in 14 months old, with chronic symptoms of ascites, poor weight gain, and then discarding chronic and infectious disease, is in the pathology of peritoneum cell discovery found typically skin. FHB diagnosis is often a challenge and must be based on the combination of light microscopy and immunohistochemistry.

\section{References}

1. American journal of otolaryngology (2013) Head and neck medicine and surgery. Elsevier 34: 154-157.

2. Ceroni D, Dayer R, De Coulon G, Kaelin A (2011) Benign fibrous histiocytoma of bone in a paediatric population: a report of 6 cases. Musculoskelet Surg 95: 107-114. [Crossref]

3. Volpicelli ER, Fletcher CD (2012) Desmin and CD34 positivity in cellular fibrous histiocytoma: an immunohistochemical analysis of 100 cases. J Cutan Pathol 39: 747 752. [Crossref]

4. Rullo R, Ferraraccio F, Serpico R, Addabbo F, Mazzarella N, et al. (2012) Oral fibrous histiocytoma and its angiomatoid variant. J Craniomaxillofac Surg 40: 435-438. [Crossref]

5. Garrido-Ruiz MC, Carrillo R, Enguita AB, Peralto JL (2009) Signet-ring cell dermatofibroma. Am J Dermatopathol 31: 84-87. [Crossref]

6. Macdonald D, Fornasier V, Holtby R (2002) Benign fibrohistiocytoma (xanthomatous variant) of the acromion. A case report and review of the literature. Arch Pathol Lab Med 126: 599-601. [Crossref]

7. Bielamowicz S, Dauer MS, Chang B, Zimmerman MC (1995) Noncutaneous benign fibrous histiocytoma of the head and neck. Otolaryngol Head Neck Surg 113: 140-146. [Crossref]

8. Sabater V, Gutierrez Herrera JM, Gaona Morales JJ (2005) Histiocitoma fibroso benigno de tejidos blandos profundos. Su diagnóstico diferencial con el dermatofibrosarcoma protuberans. $7^{\circ}$ Congreso Virtual Hispanoamericano de Anatomía Patológica.

9. Mentzel T, Kutzner H (2009) Dermatomyofibroma: clinicopathologic and immunohistochemical analysis of 56 cases and reappraisal of a rare and distinct cutaneous neoplasm. Am J Dermatopathol 31: 44-49. [Crossref]

10. Min-Suk Heo, Hyeon-Jeong Cho, Ki-Jeong Kwon, Sam-Sun Lee, Soon-Chul Choi (2004) Benign fibrous histiocytoma in the mandible. Oral radiology 97: 276-280

11. Clarke BE, Xipell JM, Thomas DP (1985) Benign fibrous histiocytoma of bone. Am J Surg Pathol 9: 806-815. [Crossref]

12. Han TY, Chang HS, Lee JH, Lee WM, Son SJ (2011) A clinical and histopathological study of 122 cases of dermatofibroma (benign fibrous histiocytoma). Ann Dermatol 23: 185-192. [Crossref]

13. Skoulakis CE, Papadakis CE, Datseris GE, Drivas EI, Kyrmizakis DE, et al. (2007) Subcutaneous benign fibrous histiocytoma of the cheek. Case report and review of the literature. Acta Otorhinolaryngol Ital 27: 90-93. [Crossref]

14. Arikanoglu Z, Akbulut S, Basbug M, Meteroglu F, Senol A, et al. (2011) Benign fibrous histiocytoma arising from the intercostal space. Gen Thorac Cardiovasc Surg 59: 763-766. [Crossref]

15. Calonje E, Mentzel T, Fletcher CD (1994) Cellular benign fibrous histiocytoma Clinicopathologic analysis of 74 cases of a distinctive variant of cutaneous fibrous histiocytoma with frequent recurrence. Am J Surg Pathol 18: 668-676.

16. Gómez-Mateo Mdel C, Monteagudo C (2013) Nonepithelial skin tumors with multinucleated giant cells. Semin Diagn Pathol 30: 58-72. [Crossref]

Copyright: (C2016 D'Amato Gutiérrez M. This is an open-access article distributed under the terms of the Creative Commons Attribution License, which permits unrestricted use, distribution, and reproduction in any medium, provided the original author and source are credited. 